\title{
Circulating levels of soluble tumor necrosis factor receptor 2 are associated with progressive diabetic kidney disease in patients with type 2 diabetes mellitus
}

\author{
Tsung-Hui Wu \\ Taipei Veterans General Hospital \\ Li-Hsin Chang \\ Yeezen General Hospital \\ Chia-Huei Chu \\ Mackay Memorial Hospital \\ Chii-Min Hwu \\ Taipei Veterans General Hospital \\ Harn-Shen Chen \\ Taipei Veterans General Hospital \\ Liang-Yu Lin ( $\square$ linly@vghtpe.gov.tw ) \\ Taipei Veterans General Hospital
}

\section{Research Article}

Keywords: soluble tumor necrosis factor receptor 2, type 2 diabetes mellitus, diabetic kidney disease

Posted Date: December 16th, 2020

DOI: https://doi.org/10.21203/rs.3.rs-126278/v1

License: (c) (i) This work is licensed under a Creative Commons Attribution 4.0 International License.

Read Full License 


\section{Abstract \\ Background}

Chronic low-grade inflammation is considered one of the major mechanisms for the progression of diabetic kidney disease. We investigated the prognostic value of circulating soluble tumor necrosis factor receptor 2 (sTNFR2) for early nephropathy in patients with type 2 diabetes.

\section{Materials and methods}

A total of 346 patients with type 2 diabetes and an estimated glomerular filtration rate (eGFR) $\geq$ $30 \mathrm{~mL} / \mathrm{min} / 1.73 \mathrm{~m}^{2}$ were followed up for a median of 4 years. Renal outcomes were defined as a composite of either or both a $>30 \%$ decline in the eGFR and/or albuminuria stage progression determined with consecutive tests.

\section{Results}

Sixty-nine patients developed renal composite events. Serum concentrations of sTNFR2 were strongly associated with the risk of renal function decline and progressive changes in albuminuria. Through a receiver operating characteristic curve analysis, a serum sTNFR2 level of $1.608 \mathrm{ng} / \mathrm{mL}$ was adopted as the discriminator value for predicting renal outcomes (area under the curve $0.61,95 \%$ confidence interval $0.54-0.68, p=0.005$ ), yielding a sensitivity of $73.9 \%$ and a specificity of $48.7 \%$. The association of sTNFR2 levels $\geq 1.608 \mathrm{ng} / \mathrm{mL}$ to renal outcomes was significant after adjusting for relevant variables (hazard ratio $1.95,95 \%$ confidence interval $1.01-3.74, p=0.046$ ) and remained consistent across subgroups stratified by age, sex, systolic blood pressure, eGFR, albuminuria, and the use of reninangiotensin system blockers.

\section{Conclusions}

Higher circulating levels of STNFR2 are independently associated with an eGFR decline and progressive albuminuria in patients with type 2 diabetes.

\section{Introduction}

Although there have been improvements in diabetes management, the prevalence of diabetic kidney disease (DKD) continues to rise due to improved patient prognoses and the growing incidence of diabetes mellitus. ${ }^{1}$ Approximately $35 \%-50 \%$ of patients with type 2 diabetes will eventually develop various kidney disorders, such as microalbuminuria, macroalbuminuria, or impaired renal function. ${ }^{1,2}$ Diabetic kidney disease is the most common cause of end stage renal disease (ESRD) worldwide, ${ }^{3}$ and the health care 
costs of DKD has increased substantially in the recent decades. ${ }^{2}$ Chronic kidney disease is the dominant contributor to excess mortality in patients with type 2 diabetes. ${ }^{4,5}$ To prevent ESRD and premature mortality, it is crucial to identify patients with high risk of advanced renal disease at an early stage and provide personalized management.

Screening of patients with diabetic nephropathy includes measuring their urinary albumin-creatinine ratio (UACR) and estimated glomerular filtration rate (eGFR) at least once annually. ${ }^{6}$ Although most patients with a risk of DKD can be identified by screening for albuminuria and eGFR, significant glomerular structural changes are often already developed by the time microalbuminuria becomes apparent. ${ }^{7}$ In addition, patients with type 2 diabetes can develop renal impairments in the absence of albuminuria; 8 thus making albuminuria an ineffective screening test for these patients. Novel biomarkers are needed to detect the early stages of diabetic kidney disease.

Inflammation has emerged as an important mechanism in the pathogenesis of DKD. ${ }^{9}$ Tumor necrosis factor alpha (TNFa) is an inflammatory cytokine produced by endothelial cells, fat, and immune cells. Binding of TNFa to the membrane receptors activates a number of signaling pathways that lead to apoptosis, proliferation, and inflammatory processes. ${ }^{10}$ The circulating level of soluble tumor necrosis factor receptor 2 (sTNFR2), which is the surface receptor of TNFa in the blood, is associated with endstage renal disease, cardiovascular disease, and mortality in patients with type 2 diabetes. ${ }^{11-14}$ However, the association of sTNFR2 with the development of early nephropathy in patients with type 2 diabetes has been investigated less often. Therefore, the aim of this study was to explore the association of sTNFR2 with early changes in diabetic nephropathy in patients with type 2 diabetes.

\section{Materials And Methods}

\section{Study design and participants}

Patients with type 2 diabetes mellitus, visiting the endocrinology and metabolism outpatient clinic at Taipei Veterans General Hospital between June 2014 and September 2019, were enrolled in the prospective observational cohort study. Patients with an eGFR $<30 \mathrm{~mL} / \mathrm{min} / 1.73 \mathrm{~m}^{2}$, as determined by the Modification of Diet in Renal Disease equation, or elevated serum levels of alanine aminotransferase greater than two-fold the upper normal limit, uncontrolled cancer, or hemoglobin $\mathrm{A} 1 \mathrm{C}$ (HbA1C) $\geq 9.0 \%$ were excluded. Baseline clinical parameters were registered, including age, sex, height, weight, blood pressure, and hip and waist circumferences. The following risk factors and comorbidities were evaluated: cardiovascular disease, hyperlipidemia, hypertension, retinopathy, neuropathy, and smoking status. Serum creatinine, $\mathrm{HbA1C}$, lipid profiles, and urine albumin and creatinine levels were measured every 6 months in the central laboratory of the Department of Clinical Pathology and Laboratory of Taipei Veterans General Hospital. The urinary albumin-creatinine ratio was used as a measure of albuminuria. Normoalbuminuria, microalbuminuria, and macroalbuminuria were defined as a UACR $<30 \mathrm{mg} / \mathrm{g}$ creatinine, $30-299 \mathrm{mg} / \mathrm{g}$ creatinine, and $\geq 300 \mathrm{mg} / \mathrm{g}$ creatinine, respectively. We measured serum sTNFR2 
levels according to the manufacturer's instructions (Quantikine ELISA kit; R\&D Systems, Minneapolis, MN, USA).

This prospective study was approved by the ethics committee at Taipei Veterans General Hospital. Informed consent was obtained from all participants, and the study complied with the guidelines of the Declaration of Helsinki.

\section{Renal outcomes}

The renal outcomes were a composite of sustained decreases in the eGFR and/or the progression of albuminuria stage. The sustained decreases in the eGFR were defined as $a>30 \%$ reduction in the eGFR from baseline in at least two consecutive samples. The progression of albuminuria stages was defined as the transition from normoalbuminuria to microalbuminuria or macroalbuminuria, or from microalbuminuria to macroalbuminuria. The progression of albuminuria stages was also confirmed by two consecutive measurements.

\section{Statistical Analyses}

The variables were expressed as percentage values for categorical data and as mean \pm standard deviation for continuous data. Univariate Cox proportional analyses were used to examine the relevant variables associated with renal composite outcomes. The association between serum sTNFR2 levels and renal outcomes was expressed as hazard ratios (HRs) and 95\% confidence intervals $(95 \% \mathrm{Cl})$. The following multivariate Cox models were built: model 1, adjusted for age and sex; model 2, adjusted for age, sex, and duration of diabetes; model 3, adjusted for retinopathy, neuropathy, eGFR, UACR, dipeptidyl peptidase-4 inhibitor, and insulin in addition to all variables in model 2. A receiver operating characteristic curve analysis was performed, and the maximum value of the sum of the sensitivity and specificity was used to yield the cut-off value of sTNFR2 for predicting the renal composite events. Differences between groups, which were stratified by the occurrence of renal outcomes or the cut-off value of sTNFR2, were analyzed by Pearson's chi-squared test for categorical data and independent analyses of variance (ANOVA) for continuous variables. The survival curve for the renal composite events was illustrated using the Kaplan-Meier method, and different groups were compared using the log-rank test. A two-sided $P$ value $<0.05$ was considered statistically significant. All analyses were performed with the use of SPSS Statistics version 22 (IBM Corporation, Armonk, NY, USA).

\section{Results}

\section{Study patients}

A total of 346 patients were enrolled in the study. The mean age of the patients was 61.3 years, and $69.7 \%$ of the patients were men. The mean duration of diabetes was 11.1 years. One-third of the subjects had albuminuria, and the prevalence of retinopathy and neuropathy was $9.2 \%$. Sixty-four (18.5\%) patients had stage 3 chronic kidney disease. The mean $\mathrm{HbA} 1 \mathrm{C}$ was $7.1 \%$, mean blood pressure was $114.6 \mathrm{mmHg}$, 
and mean body mass index (BMI) was $26.3 \mathrm{~kg} / \mathrm{m}^{2}$. The baseline characteristics of the study population are summarized in Table 1.

\section{Association of sTNFR2 with the renal outcomes}

Over a median follow-up time of 4 years, 69 participants had a renal composite event, which is composed of 44 events of progression of albuminuria stages and 25 events of a $>30 \%$ reduction in the eGFR. Among the 44 events of progressive albuminuria, 21 participants had a transition from normoalbuminuria to microalbuminuria, and 22 participants progressed from microalbuminuria to macroalbuminuria. One patient had a rapid progression from normoalbuminuria to macroalbuminuria. Patients with renal composite events had longer durations of diabetes, higher percentages of retinopathy or neuropathy, higher UACRs, and lower eGFRs at baseline. The coverage of the renin-angiotensin system (RAS) blockade was more extensive in patients with renal outcomes (Table 1). Correlations between sTNFR2 concentrations and BMIs or waist-to-hip ratios were weak (Pearson's correlation coefficient -0.057 for sTNFR2 and BMI, $p=0.292 ;-0.015$ for sTNFR2 and waist-hip-ratio, $p=0.778$ ). The sTNFR2 concentration was associated with the renal outcomes in the univariate Cox proportional analysis (hazard ratio [HR] 1.27, 95\% confidence interval $[\mathrm{Cl}] 1.05-1.53, p=0.013$ ). Other clinical covariates, such as the duration of diabetes, presence of retinopathy or neuropathy, eGFR and UACR at baseline, and the use of RAS inhibitors were also associated with renal outcomes. The association of sTNFR2 concentration with renal events was attenuated after adjustment in sequential models (Table 2).

The ideal cut-off point for sTNFR2 concentration is the point where true-positive findings and few falsepositive results are detected in most patients. The optimal cut-off value of sTNFR2 levels obtained using the receiver operating characteristic curve analysis was $1.608 \mathrm{ng} / \mathrm{mL}$, allowing for a sensitivity of $73.9 \%$ and a specificity of $48.7 \%$. The area under the receiver operating characteristic curve of sTNFR2 was 0.61 (95\% $\mathrm{Cl}$ 0.54-0.68, $\mathrm{p}=0.005$; Figure 1). The highest tertile of sTNFR2 concentration had an increased risk of renal composite events ( $p=0.035$ from the log-rank test; Figure $2 a)$.

\section{Association of sTNFR2 levels $\geq 1.608 \mathrm{ng} / \mathrm{mL}$ with the renal outcomes}

The clinical characteristics of the study population stratified based on STNFR2 concentrations $(\geq 1.608$ $\mathrm{ng} / \mathrm{mL}$ or $<1.608 \mathrm{ng} / \mathrm{mL}$ ) are shown in Supplementary Table 1 . The patients with sTNFR2 concentrations $\geq 1.608 \mathrm{ng} / \mathrm{mL}$ were older and had longer durations of diabetes, higher UACRs, and lower eGFRs at baseline. The coverage of the RAS blockade was more extensive in patients with sTNFR2 concentrations $\geq 1.608 \mathrm{ng} / \mathrm{mL}$ than in patients with sTNFR2 concentrations $<1.608 \mathrm{ng} / \mathrm{mL}(55.4 \% \mathrm{vs} .39 .9 \%, \mathrm{p}=0.004)$. The patients with sTNFR2 concentrations $\geq 1.608 \mathrm{ng} / \mathrm{mL}$ had more renal composite events at the end of the study than those with sTNFR2 concentrations $<1.608 \mathrm{ng} / \mathrm{mL}$ did $(26.4 \%$ vs. $11.8 \%$; $\mathrm{p}=0.005$ from the log-rank test; Figure $2 b$ ). Regarding the separate components of the renal composite events, the frequency of worsening albuminuria was also higher in the study group with sTNFR2 concentrations $\geq 1.608 \mathrm{ng} / \mathrm{mL}$ (17.1\% vs. $7.8 \%$ for worsening albuminuria, $p=0.011$; Supplementary Table 1 ). 
In the univariate Cox proportional analysis, sTNFR2 concentrations $\geq 1.608 \mathrm{ng} / \mathrm{mL}$ were associated with higher renal event rates (HR 2.07, 95\% $\mathrm{Cl} 1.21-3.54, \mathrm{p}=0.008$ ). A sTNFR2 concentration $\geq 1.608 \mathrm{ng} / \mathrm{mL}$ predicted renal events in all of the multivariate models (HR 2.05, 95\% Cl 1.17-3.61, $\mathrm{p}=0.013$ for model 1 ; HR 2.01, 95\% Cl 1.14-3.53, $p=0.016$ for model 2; HR 1.95, 95\% Cl 1.01-3.74, $p=0.046$ for model 3 ).

We performed a subgroup analysis based on age (younger or older than 60 years), sex, systolic blood pressure ( $\geq$ or $<140 \mathrm{mmHg}$ ), eGFR ( $\geq$ or $<60 \mathrm{~mL} / \mathrm{min} / 1.73 \mathrm{~m}^{2}$ ), UACR ( $\geq$ or $<30 \mathrm{mg} / \mathrm{g}$ creatinine), and the use of RAS inhibitors. The association of a sTNFR2 concentration $\geq 1.608 \mathrm{ng} / \mathrm{mL}$ with renal outcomes remained significant across all subgroups, including patients with an eGFR $\geq 60 \mathrm{~mL} / \mathrm{min} / 1.73 \mathrm{~m}^{2}$ or normoalbuminuria (Table 3).

\section{Discussion}

In our study, elevated serum sTNFR2 concentrations were associated with worsening albuminuria and progressive eGFR decline in patients with type 2 diabetes. Circulating sTNFR2 levels $\geq 1.608 \mathrm{ng} / \mathrm{mL}$ were a strong predictor of the progression of albuminuria and renal impairment in patients with type 2 diabetes, and the association was independent of relevant clinical covariates, including age, duration of diabetes, baseline UACR and eGFR, and the use of RAS inhibitors.

In addition to the traditional risk factors, such as poor glycemic ${ }^{15}$ or blood pressure ${ }^{16}$ control, chronic lowgrade inflammation plays an important role in the development of DKD. ${ }^{9}$ Activation of TNF pathways is associated with renal function decline in patients with chronic kidney disease. ${ }^{17}$ Tumor necrosis factor alpha is involved in the signal transduction pathways by interacting with two types of membrane receptors: tumor necrosis factor receptor (TNFR) 1 and TNFR2. ${ }^{18}$ Tumor necrosis factor receptor 1 is mainly present in glomerular and tubular endothelial cells, whereas TNFR2 is usually absent in normal kidneys and transcriptionally expressed in the renal cells in various kidney diseases. ${ }^{19}$ Tumor necrosis factor receptor 1 and TNFR2 induce shared and distinctive signalling pathways that lead to apoptosis, proliferation, and inflammation. ${ }^{9}$ Both membrane-bound receptors TNFR1 and TNFR2 can be cleaved by the metalloproteinase and released as circulating polypeptides, soluble TNFR1 (sTNFR1) and sTNFR2. ${ }^{20}$ Higher serum STNFR2 concentrations have been proven to be associated with increased risks of renal function decline or ESRD in patients with type 2 diabetes. ${ }^{11-14}$ In one cohort of American Indians (Pima Indians) with type 2 diabetes, patients with macroalbuminuria whose serum sTNFR2 levels were in the highest quartile had a $88.7 \%$ cumulative incidence of ESRD, whereas those with macroalbuminuria and sTNFR2 levels in the lowest three quartiles had a $47.3 \%$ cumulative incidence of ESRD at 10 years of follow-up. ${ }^{13}$ Higher sTNFR2 levels were associated with all-cause mortality as well. ${ }^{11}$ The findings in our cohort suggested that sTNFR2 is a promising biomarker in the early stages of diabetic nephropathy. The association of sTNFR2 concentration $\geq 1.608 \mathrm{ng} / \mathrm{mL}$ with renal outcomes remained significant in all subgroups, including patients with eGFRs $\geq 60 \mathrm{~mL} / \mathrm{min} / 1.73 \mathrm{~m}^{2}$ or normoalbuminuria. 
Soluble tumor necrosis factor receptor 1 has been considered a valuable predictor of renal function decline among patients with type 2 diabetes. ${ }^{11-14,21,22}$ A recent meta-analysis demonstrated that both circulating sTNFR1 and sTNFR2 levels were independently associated with DKD progression in more than 5000 patients with diabetes. ${ }^{23}$ We previously reported that serum sTNFR1 levels were associated with renal outcomes in patients with type 2 diabetes. ${ }^{10}$ The association of serum STNFR1 levels above the cutoff value yielded by the receiver operating characteristic curve analysis with DKD progression was significant after adjusting for relevant clinical variables (HR 2.43, 95\% $\mathrm{Cl} 1.18-5.02, \mathrm{p}=0.01)$. Although the hazard ratios calculated for renal outcomes according to the serum sTNFR1 levels were higher than those calculated for serum sTNFR2 levels, the Cls for the hazard ratios overlapped.

Patients with type 2 diabetes and renal impairments do not always have preceding albuminuria. ${ }^{24}$ In the United Kingdom Prospective Diabetes Study (UKPDS) cohort, $51 \%$ of the patients with renal impairments had normoalbuminuria for a median of 15 years of follow-up. ${ }^{25}$ The presence of nonproteinuric renal dysfunction in patients with type 2 diabetes increases their risk of ESRD and cardiovascular disease. ${ }^{26}$ Increased vascular resistance in renal interlobar arteries has been suggested to cause damage to nephron structures, contributing to nonproteinuric diabetic nephropathy. ${ }^{27}$ Tumor necrosis factor alpha is an essential mediator of inflammation that can induce renal vasoconstriction, which is a potential mechanism of nonproteinuric diabetic nephropathy. ${ }^{28}$ In our study, the association of serum sTNFR2 levels with renal composite events was consistent across multiple prespecified subgroups, including participants with and without albuminuria. This finding identified STNFR2 as a potential predictor of renal function decline in patients with type 2 diabetes and normoalbuminuria.

There may be a racial disparity in serum sTNFR2 levels among patients with type 2 diabetes. The median serum sTNFR2 level in Pima Indians $(4835 \mathrm{pg} / \mathrm{mL})^{13}$ was much higher than that in Caucasian patients in the Joslin Study of the Genetics of Type 2 Diabetes and Kidney Complications $(2527 \mathrm{pg} / \mathrm{mL}){ }^{12}$ although increased serum sTNFR2 levels in Pima Indians may be partly attributed to obesity. In a previous study comprising of Japanese patients, ${ }^{29}$ the median serum sTNFR2 level in participants with an eGFR $\geq$ $60 \mathrm{~mL} / \mathrm{min} / 1.73 \mathrm{~m}^{2}$ was $2972 \mathrm{pg} / \mathrm{mL}$, which was comparable with that in Caucasians. The serum sTNFR2 levels in our study did not seem markedly different from those of previous studies, and the results from our cohort still imply that sTNFR2 could be a potential predictor of renal outcomes in patients with type 2 diabetes. Further studies are needed to clarify the normal ranges among different races.

The limitations of our study should be considered. First, the participants in this cohort were recruited from a single center, and we could not avoid a selection bias completely. Second, we estimated glomerular filtration rates from a serum creatinine-based equation, which are less accurate than estimates that are based on serum cystatin $\mathrm{C}$ or direct measurements of renal function. Direct measurement of the GFR may augment the strength of the association. Third, sodium/glucose co-transporter 2 (SGLT2) inhibitors and glucagon-like peptide-1 (GLP-1) analogues have renoprotective actions in patients with type 2 diabetes beyond glycemic control. ${ }^{30}$ Patients in our cohort rarely used sodium/glucose co-transporter 2 inhibitors 
or glucagon-like peptide-1 analogues because of the restricted reimbursement policies for them, owing to their high acquisition costs. Finally, the prospective observational design does not necessarily imply a causal relationship. Further studies are required to confirm that interventions to circulating sTNFR2 levels contribute to beneficial effects on DKD progression.

\section{Conclusions}

Circulating sTNFR2 levels are associated with the progression of diabetic kidney disease in patients with type 2 diabetes independent of baseline albuminuria or renal function. Soluble tumor necrosis factor receptor 2 is a potential prognostic biomarker for the personalized management of worsening diabetic nephropathy.

\section{Declarations}

\section{Acknowledgments}

This study was supported by research grants V104E11-004-MY2, V105C-131, V107C-201, V108C-197, V109C-179 and V110C-198 provided to L.Y.L. from Taipei Veterans General Hospital and No. 2021001 to L.H.C. from Yeezen General Hospital. The authors thank the Medical Sciences \& Technology Building of Taipei Veterans General Hospital for providing experimental space and facilities.

The authors declare no conflicts of interest regarding the contents of this manuscript.

\section{Author contributions}

Study design and data collection: T.H.W., and L.Y.L.

Case contributor: C.H.C., C.M.H., H.S.C., and L.Y.L.

Analysis data: T.H.W., L.H.C., and L.Y.L.

Writing the manuscript: T.H.W., and L.Y.L.

\section{References}

1. Thomas MC, Brownlee M, Susztak K, et al. Diabetic kidney disease. Nature Rev Dis 2015;1:15018.

2. Saran R, Robinson B, Abbott KC, et al. US renal data system 2017 annual data report: epidemiology of kidney disease in the United States. Am J Kidney Dis 2018;71:A7.

3. Afkarian M, Zelnick LR, Hall YN, et al. Clinical manifestations of kidney disease among US adults with diabetes, 1988-2014. Jama 2016;316:602-610.

4. Groop PH, Thomas MC, Moran JL, et al. The presence and severity of chronic kidney disease predicts all-cause mortality in type 1 diabetes. Diabetes 2009;58:1651-1658. 
5. Afkarian M, Sachs MC, Kestenbaum B, et al. Kidney disease and increased mortality risk in type 2 diabetes. JASN 2013;24:302-308.

6. KDOQI clinical practice guidelines and clinical practice recommendations for diabetes and chronic kidney disease. Am J Kidney Dis 2007;49:S12-154.

7. Satchell SC, Tooke JE. What is the mechanism of microalbuminuria in diabetes: a role for the glomerular endothelium? Diabetologia 2008;51:714-725.

8. Tsalamandris C, Allen TJ, Gilbert RE, et al. Progressive decline in renal function in diabetic patients with and without albuminuria. Diabetes 1994;43:649-655.

9. Murakoshi M, Gohda T, Suzuki Y. Circulating tumor necrosis factor receptors: a potential biomarker for the progression of diabetic kidney disease. Intl J Mol Sci 2020;2.

10. Chang LH, Hwu CM, Lin YC, et al. Soluble tumor necrosis factor receptor type 1 levels exhibit the better association with renal outocmes than traditional risk factors in Chinese subjects with type 2 diabetes mellitus. Endocr Prac 2020;26:1115-1124.

11. Carlsson AC, Östgren CJ, Nystrom FH, et al. Association of soluble tumor necrosis factor receptors 1 and 2 with nephropathy, cardiovascular events, and total mortality in type 2 diabetes. Cardiovasc diabetolol 2016;15:40.

12. Niewczas MA, Gohda T, Skupien J, et al. Circulating TNF receptors 1 and 2 predict ESRD in type 2 diabetes. J Am Soc Nephrol 2012;23:507-515.

13. Pavkov ME, Nelson RG, Knowler WC, Cheng Y, Krolewski AS, Niewczas MA. Elevation of circulating TNF receptors 1 and 2 increases the risk of end-stage renal disease in American Indians with type 2 diabetes. Kidney Int 2015;87:812-819.

14. Coca SG, Nadkarni GN, Huang Y, et al. Plasma biomarkers and kidney function decline in early and established diabetic kidney disease. J Am Soc Nephrol 2017;28:2786-2793.

15. Holman RR, Paul SK, Bethel MA, Matthews DR, Neil HA. 10-year follow-up of intensive glucose control in type 2 diabetes. N Engl J Med 2008;359:1577-1589.

16. Schmitz A, Vaeth M, Mogensen CE. Systolic blood pressure relates to the rate of progression of albuminuria in NIDDM. Diabetologia 1994;37:1251-1258.

17. Amdur RL, Feldman HI, Gupta J, et al. Inflammation and progression of CKD: the CRIC study. Clin J Am Soc Nephrol 2016;11:1546-1556.

18. Hehlgans T, Pfeffer K. The intriguing biology of the tumour necrosis factor/tumour necrosis factor receptor superfamily: players, rules and the games. Immunology 2005;115:1-20.

19. Al-Lamki RS, Mayadas TN. TNF receptors: signaling pathways and contribution to renal dysfunction. Kidney Int 2015;87:281-296.

20. Speeckaert MM, Speeckaert R, Laute M, Vanholder R, Delanghe JR. Tumor necrosis factor receptors: biology and therapeutic potential in kidney diseases. Am J Nephrol 2012;36:261-270.

21. Barr ELM, Barzi F, Hughes JT, et al. High baseline levels of tumor necrosis factor receptor 1 are associated with progression of kidney disease in indigenous Australians with diabetes: the eGFR 
follow-up study. Diabetes care 2018;41:739-747.

22. Saulnier PJ, Gand E, Velho G, et al. Association of circulating biomarkers (adrenomedullin, TNFR1, and NT-proBNP) with renal function decline in patients with type 2 diabetes: a french prospective cohort. Diabetes care 2017;40:367-374.

23. Ye X, Luo T, Wang K, et al. Circulating TNF receptors 1 and 2 predict progression of diabetic kidney disease: a meta-analysis. Diabetes Metab Res Rev 2019;35:e3195.

24. Thomas MC, Macisaac RJ, Jerums G, et al. Nonalbuminuric renal impairment in type 2 diabetic patients and in the general population (national evaluation of the frequency of renal impairment cOexisting with NIDDM [NEFRON] 11). Diabetes care 2009;32:1497-1502.

25. Retnakaran R, Cull CA, Thorne KI, Adler Al, Holman RR. Risk factors for renal dysfunction in type 2 diabetes: U.K. prospective diabetes study 74. Diabetes 2006;55:1832-1839.

26. Ninomiya T, Perkovic V, de Galan BE, et al. Albuminuria and kidney function independently predict cardiovascular and renal outcomes in diabetes. J Am Soc Nephrol 2009;20:1813-1821.

27. Nakao K, Uzu T, Araki S, et al. Arterial stiffness and renal impairment in non-proteinuric type 2 diabetic patients. J Diabetes Investig 2012;3:86-91.

28. Kopel J, Pena-Hernandez C, Nugent K. Evolving spectrum of diabetic nephropathy. World J Diabetes 2019;10:269-279.

29. Kamei N, Yamashita M, Nishizaki Y, et al. Association between circulating tumor necrosis factorrelated biomarkers and estimated glomerular filtration rate in type 2 diabetes. Sci Rep 2018;8:15302.

30. Alicic RZ, Rooney MT, Tuttle KR. Diabetic kidney disease: challenges, progress, and possibilities. Clin J Am Soc Nephrol 2017;12:2032-2045

\section{Tables}


Table 1. Baseline characteristics of the entire study population and according to the occurrence of the renal outcomes

\begin{tabular}{|c|c|c|c|c|}
\hline & \multirow{3}{*}{$\begin{array}{l}\text { Entire cohort } \\
(n=346)\end{array}$} & \multicolumn{3}{|c|}{$\begin{array}{l}\text { Occurrence of the renal } \\
\text { outcomes }\end{array}$} \\
\hline & & Yes & No & $\mathrm{P}$ \\
\hline & & $(n=69)$ & $(n=277)$ & \\
\hline Age & $61.3 \pm 12.8$ & $63.6 \pm 11.8$ & $60.8 \pm 13.1$ & 0.104 \\
\hline Male sex (\%) & $241(69.7)$ & $46(66.7)$ & $195(70.4)$ & 0.546 \\
\hline Smoking (\%) & $107(30.9)$ & 19 (27.5) & $88(31.8)$ & 0.496 \\
\hline Coronary artery disease (\%) & $65(18.8)$ & $20(29.0)$ & $45(16.2)$ & 0.015 \\
\hline Hyperlipidemia (\%) & $288(83.2)$ & $56(81.2)$ & $232(83.8)$ & 0.606 \\
\hline Hypertension (\%) & $210(60.7)$ & $45(65.2)$ & 165 (59.6) & 0.390 \\
\hline Retinopathy (\%) & $32(9.2)$ & $14(20.3)$ & $18(6.5)$ & $<0.001$ \\
\hline Neuropathy (\%) & $32(9.2)$ & $12(17.4)$ & $20(7.2)$ & 0.009 \\
\hline Albuminuria (\%) & $116(33.5)$ & $33(47.8)$ & $83(30.0)$ & 0.005 \\
\hline CKD stage $3(\%)$ & $64(18.5)$ & 21 (30.4) & $43(15.5)$ & 0.004 \\
\hline CKD stage 3 with albuminuria (\%) & $40(11.6)$ & $15(21.7)$ & $25(9.0)$ & 0.003 \\
\hline Duration of diabetes (year) & $11.1 \pm 7.6$ & $13.8 \pm 9.2$ & $10.5 \pm 7.0$ & 0.006 \\
\hline Body mass index & $26.3 \pm 4.4$ & $26.3 \pm 5.7$ & $26.3 \pm 4.0$ & 0.989 \\
\hline Waist-hip ratio & $0.94 \pm 0.07$ & $0.94 \pm 0.07$ & $0.93 \pm 0.07$ & 0.603 \\
\hline Systolic blood pressure (mmHg) & $132.9 \pm 15.5$ & $133.4 \pm 16.0$ & $132.8 \pm 15.3$ & 0.769 \\
\hline Diastolic blood pressure (mmHg) & $78.0 \pm 11.4$ & $77.6 \pm 11.9$ & $78.1 \pm 11.3$ & 0.782 \\
\hline Mean blood pressure (mmHg) & $114.6 \pm 12.8$ & $114.8 \pm 13.4$ & $114.6 \pm 12.7$ & 0.877 \\
\hline Urinary albumin-creatinine ratio (mg/g Cr) & $107.1 \pm 308.1$ & $264.8 \pm 538.6$ & $69.3 \pm 204.0$ & 0.006 \\
\hline HbA1C (\%) & $7.1 \pm 0.8$ & $7.2 \pm 0.8$ & $7.0 \pm 0.8$ & 0.069 \\
\hline Total cholesterol (mg/dL) & $167.4 \pm 28.0$ & $166.5 \pm 25.5$ & $167.7 \pm 28.6$ & 0.766 \\
\hline Creatinine (mg/dL) & $0.96 \pm 0.26$ & $1.03 \pm 0.33$ & $0.95 \pm 0.24$ & 0.055 \\
\hline eGFR (mL/min/1.73m²) & $78.0 \pm 19.3$ & $71.5 \pm 19.8$ & $79.6 \pm 18.8$ & 0.002 \\
\hline sTNFR2 (ng/mL) & $2.03 \pm 1.16$ & $2.35 \pm 1.21$ & $1.96 \pm 1.14$ & 0.011 \\
\hline Metformin (\%) & 269 (77.7) & 54 (78.3) & 215 (77.6) & 0.908 \\
\hline
\end{tabular}




\begin{tabular}{|lllll|}
\hline Sulfonylurea (\%) & $135(39.0)$ & $30(43.5)$ & $105(37.9)$ & 0.396 \\
\hline Dipeptidyl peptidase-4 inhibitor (\%) & $62(17.9)$ & $17(24.6)$ & $45(16.2)$ & 0.104 \\
\hline $\begin{array}{l}\text { Sodium/glucose co-transporter 2 inhibitor } \\
(\%)\end{array}$ & $7(2.0)$ & $1(1.4)$ & $6(2.2)$ & 0.705 \\
\hline Insulin (\%) & $61(17.6)$ & $15(21.7)$ & $46(16.6)$ & 0.317 \\
\hline Renin-angiotensin system blockade (\%) & $168(48.6)$ & $42(60.9)$ & $126(45.5)$ & 0.022 \\
\hline Diuretics (\%) & $40(11.6)$ & $11(15.9)$ & $29(10.5)$ & 0.203 \\
\hline
\end{tabular}

Data are expressed as mean \pm SD for continuous variables and numbers and percentages for noncontinuous variables.

CKD, chronic kidney disease; $\mathrm{Cr}$, creatinine; $\mathrm{HbA} 1 \mathrm{C}$, hemoglobin $\mathrm{A} 1 \mathrm{C}$; eGFR, estimated glomerular filtration rate; sTNFR2, soluble tumor necrosis factor receptor type 2 .

Table 2. Results of the univariate and multivariate Cox proportional hazard models for the association of sTNFR2 with renal composite events

\begin{tabular}{|llll|}
\hline STNFR2 & HR & $95 \% \mathrm{Cl}$ & P value \\
\hline STNFR2 $\geq 1.608 \mathrm{ng} / \mathrm{mL}$ & 1.27 & $1.05-1.53$ & 0.013 \\
\hline Duration of diabetes & 2.07 & $1.21-3.54$ & 0.008 \\
\hline Retinopathy & 1.04 & $1.01-1.07$ & 0.008 \\
\hline Neuropathy & 2.75 & $1.53-4.94$ & 0.001 \\
\hline eGFR & 1.89 & $1.01-3.51$ & 0.046 \\
\hline UACR (per $100 \mathrm{mg} / \mathrm{g}$ Crincrease) & 0.98 & $0.97-0.99$ & 0.004 \\
\hline RAS inhibitors & 1.09 & $1.05-1.14$ & $<0.001$ \\
\hline Model 1 for sTNFR2 & 1.66 & $1.03-2.70$ & 0.039 \\
\hline Model 2 for sTNFR2 & 1.26 & $1.03-1.53$ & 0.022 \\
\hline Model 3 for sTNFR2 & 1.23 & $1.00-1.51$ & 0.047 \\
\hline Model 1 for sTNFR2 $\geq 1.608 \mathrm{ng} / \mathrm{mL}$ & 1.01 & $0.77-1.34$ & 0.928 \\
\hline Model 2 for sTNFR2 $\geq 1.608 \mathrm{ng} / \mathrm{mL}$ & 2.05 & $1.17-3.61$ & 0.013 \\
\hline Model 3 for sTNFR2 $\geq 1.608 \mathrm{ng} / \mathrm{mL}$ & 2.01 & $1.14-3.53$ & 0.016 \\
\hline
\end{tabular}


Model 1: adjusted for age and sex.

Model 2: adjusted for age, sex, and duration of diabetes.

Model 3: adjusted for age, sex, duration of diabetes, retinopathy, neuropathy, eGFR, UACR, and RAS inhibitors.

$\mathrm{HR}$, hazard ratio; $\mathrm{Cl}$, confidence interval; sTNFR2, soluble tumor necrosis factor receptor type 2; eGFR, estimated glomerular filtration rate; $\mathrm{UACR}$, urinary albumin-creatinine ratio; $\mathrm{Cr}$, creatinine; RAS, reninangiotensin system.

Table 3. Results of the association between sTNFR2 concentrations $\geq 1.608 \mathrm{ng} / \mathrm{mL}$ and renal composite events stratified by age, sex, systolic blood pressure, eGFR, UACR, and the use of RAS inhibitors.

\begin{tabular}{|c|c|c|c|}
\hline \multirow[t]{2}{*}{ Subgroup } & Crude & $95 \% \mathrm{Cl}$ & $P$ value for interaction \\
\hline & \multicolumn{3}{|l|}{$\mathrm{HR}$} \\
\hline Age $\geq 60$ years old $(n=209)$ & 2.19 & $0.98-4.91$ & 0.86 \\
\hline Age $<60$ years old $(n=137)$ & 2.25 & $1.01-5.03$ & \\
\hline Male sex $(n=241)$ & 1.65 & $0.89-3.07$ & 0.16 \\
\hline Female sex $(n=105)$ & 3.96 & $1.17-13.33$ & \\
\hline $\mathrm{SBP} \geq 140 \mathrm{mmHg}(\mathrm{n}=106)$ & 2.67 & $0.90-7.96$ & 0.65 \\
\hline $\mathrm{SBP}<140 \mathrm{mmHg}(\mathrm{n}=240)$ & 1.87 & $1.00-3.49$ & \\
\hline $\mathrm{eGFR} \geq 60 \mathrm{ml} / \mathrm{min} / 1.73 \mathrm{~m}^{2}(\mathrm{n}=282)$ & 1.88 & $1.03-3.44$ & 0.66 \\
\hline $\mathrm{eGFR}<60 \mathrm{ml} / \mathrm{min} / 1.73 \mathrm{~m}^{2}(\mathrm{n}=64)$ & 1.36 & $0.32-5.90$ & \\
\hline UACR $\geq 30 \mathrm{mg} / \mathrm{g} \mathrm{Cr}(\mathrm{n}=116)$ & 1.84 & $0.71-4.78$ & 0.21 \\
\hline UACR $<30 \mathrm{mg} / \mathrm{g} \mathrm{Cr}(\mathrm{n}=230)$ & 1.82 & $0.92-3.60$ & \\
\hline RAS inhibitors $(n=168)$ & 2.42 & $1.12-5.24$ & 0.26 \\
\hline No RAS inhibitors $(\mathrm{n}=178)$ & 1.53 & $0.70-3.36$ & \\
\hline
\end{tabular}

$\mathrm{HR}$, hazard ratio; $\mathrm{Cl}$, confidence interval; SBP, systolic blood pressure; eGFR, estimated glomerular filtration rate; UACR, urinary albumin-creatinine ratio; $\mathrm{Cr}$, creatinine; RAS, renin-angiotensin system. 
Table S1. Baseline characteristics and renal composite events of patients grouped according to soluble tumor necrosis factor receptor type 2 (sTNFR2) concentrations

\begin{tabular}{|c|c|c|c|}
\hline & sTNFR2 & & \\
\hline & $\begin{array}{l}\geq 1.608 \mathrm{ng} / \mathrm{mL} \\
(\mathrm{n}=193)\end{array}$ & $\begin{array}{l}<1.608 \mathrm{ng} / \mathrm{mL} \\
(\mathrm{n}=153)\end{array}$ & $P$ value \\
\hline Age & $65.0 \pm 11.7$ & $56.7 \pm 12.7$ & $<0.001$ \\
\hline Male sex (\%) & $129(66.8)$ & $112(73.2)$ & 0.201 \\
\hline Smoking (\%) & $57(29.5)$ & $50(32.7)$ & 0.529 \\
\hline Coronary artery disease (\%) & $43(22.3)$ & $22(14.4)$ & 0.062 \\
\hline Hyperlipidemia (\%) & $162(83.9)$ & $126(82.4)$ & 0.695 \\
\hline Hypertension (\%) & $127(65.8)$ & $83(54.2)$ & 0.029 \\
\hline Retinopathy (\%) & $23(11.9)$ & $9(5.9)$ & 0.054 \\
\hline Neuropathy (\%) & $23(11.9)$ & $9(5.9)$ & 0.054 \\
\hline Albuminuria (\%) & $80(41.5)$ & $36(23.5)$ & $<0.001$ \\
\hline CKD stage $3(\%)$ & $53(27.5)$ & $11(7.2)$ & $<0.001$ \\
\hline CKD stage 3 with albuminuria (\%) & $32(16.6)$ & $8(5.2)$ & 0.001 \\
\hline Duration of diabetes (year) & $12.1 \pm 7.7$ & $9.9 \pm 7.3$ & 0.01 \\
\hline Body mass index & $25.9 \pm 4.7$ & $26.7 \pm 4.0$ & 0.133 \\
\hline Waist-hip ratio & $0.93 \pm 0.06$ & $0.94 \pm 0.07$ & 0.342 \\
\hline Systolic blood pressure $(\mathrm{mmHg})$ & $133.6 \pm 15.7$ & $132.1 \pm 15.1$ & 0.369 \\
\hline Diastolic blood pressure (mmHg) & $78.1 \pm 12.5$ & $77.8 \pm 9.8$ & 0.802 \\
\hline Mean blood pressure $(\mathrm{mmHg})$ & $115.1 \pm 13.3$ & $114.0 \pm 12.2$ & 0.425 \\
\hline Urinary albumin-creatinine ratio $(\mathrm{mg} / \mathrm{g} \mathrm{Cr})$ & $151.6 \pm 381.3$ & $50.8 \pm 160.5$ & 0.001 \\
\hline HbA1C (\%) & $7.1 \pm 0.8$ & $7.0 \pm 0.9$ & 0.48 \\
\hline Total cholesterol (mg/dL) & $167.5 \pm 29.8$ & $167.3 \pm 25.6$ & 0.955 \\
\hline Creatinine (mg/dL) & $1.02 \pm 0.30$ & $0.89 \pm 0.19$ & $<0.001$ \\
\hline eGFR (mL/min/1.73m²) & $72.2 \pm 19.1$ & $85.5 \pm 16.8$ & $<0.001$ \\
\hline sTNFR2 (ng/mL) & $2.77 \pm 1.06$ & $1.10 \pm 0.26$ & NA \\
\hline Metformin (\%) & $146(75.6)$ & $123(80.4)$ & 0.292 \\
\hline Sulfonylurea (\%) & 75 (38.9) & $60(39.2)$ & 0.946 \\
\hline
\end{tabular}




\begin{tabular}{|llll|}
\hline Dipeptidyl peptidase-4 inhibitor (\%) & $37(19.2)$ & $25(16.3)$ & 0.495 \\
\hline Sodium/glucose co-transporter 2 inhibitor (\%) & $2(1.0)$ & $5(3.3)$ & 0.143 \\
\hline Insulin (\%) & $34(17.6)$ & $27(17.6)$ & 0.994 \\
\hline Renin-angiotensin system blockade (\%) & $107(55.4)$ & $61(39.9)$ & 0.004 \\
\hline Diuretics (\%) & $28(14.5)$ & $12(7.8)$ & 0.054 \\
\hline Renal composite events (\%) & $51(26.4)$ & $18(11.8)$ & 0.001 \\
\hline eGFR decline > 30\% (\%) & $24(12.4)$ & $10(6.5)$ & 0.067 \\
\hline Worsening albuminuria (\%) & $33(17.1)$ & $12(7.8)$ & 0.011 \\
\hline
\end{tabular}

Data are expressed as mean \pm SD for continuous variables and numbers and percentages for noncontinuous variables.

CKD, chronic kidney disease; $\mathrm{Cr}$, creatinine; $\mathrm{HbA} 1 \mathrm{C}$, hemoglobin A1C; eGFR, estimated glomerular filtration rate; sTNFR2, soluble tumor necrosis factor receptor type 2; NA, not applicable.

\section{Figures}




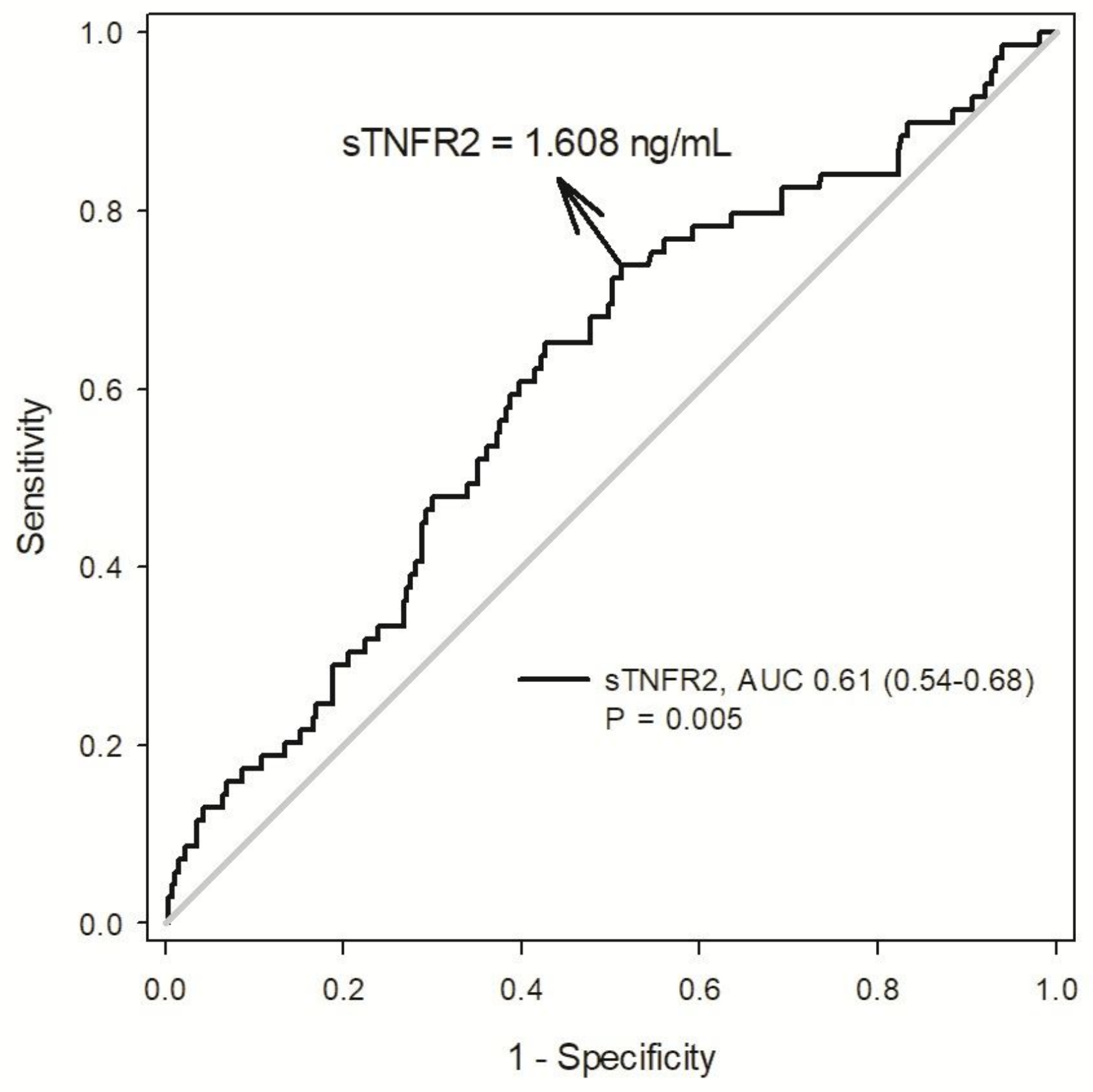

Figure 1

Receiver operating characteristic curves of soluble tumor necrosis factor receptor 2 (sTNFR2) in patients with type 2 diabetes. 


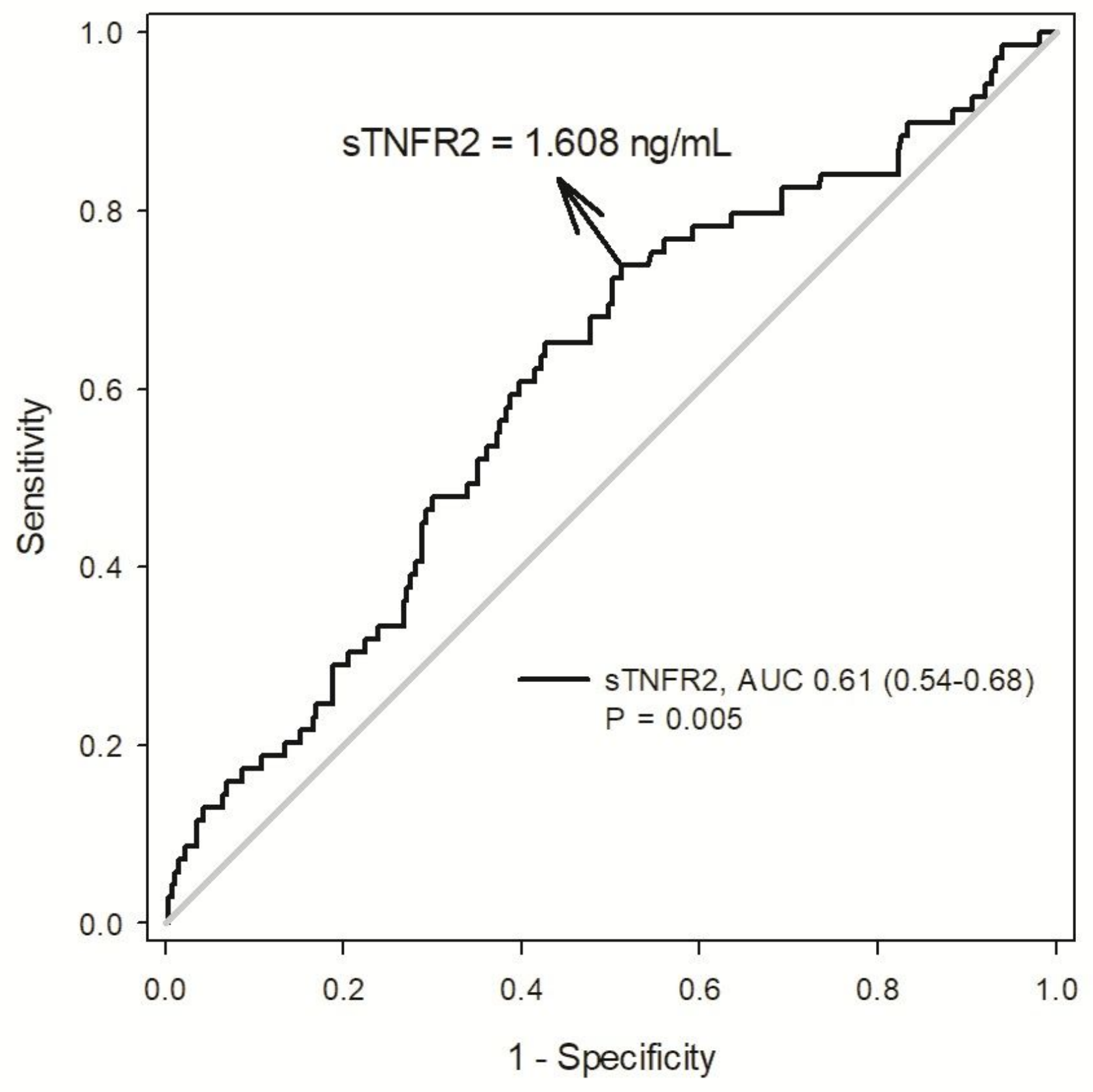

Figure 1

Receiver operating characteristic curves of soluble tumor necrosis factor receptor 2 (sTNFR2) in patients with type 2 diabetes. 

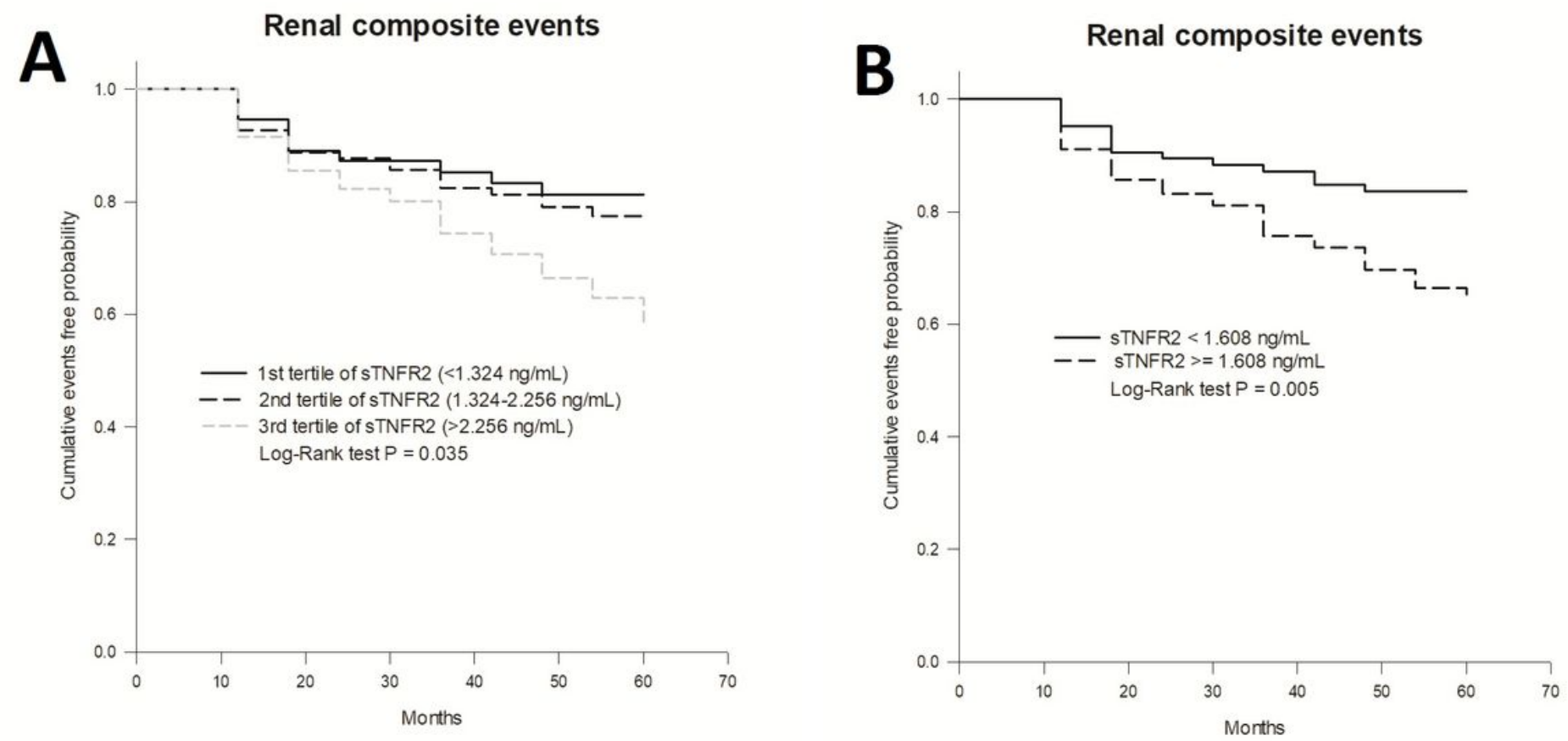

Figure 2

Kaplan-Meier curves of cumulative event-free survival of renal events (a composite of a $>30 \%$ reduction of the estimated glomerular filtration rate and/or the progression of albuminuria stages) in patients with type 2 diabetes according to: (a) the tertiles of soluble tumor necrosis factor receptor 2 (sTNFR2) levels and (b) the threshold value of sTNFR2 $(\geq 1.608 \mathrm{ng} / \mathrm{mL}$ vs. $<1.608 \mathrm{ng} / \mathrm{mL})$. Differences between curves were analyzed with log-rank statistics.
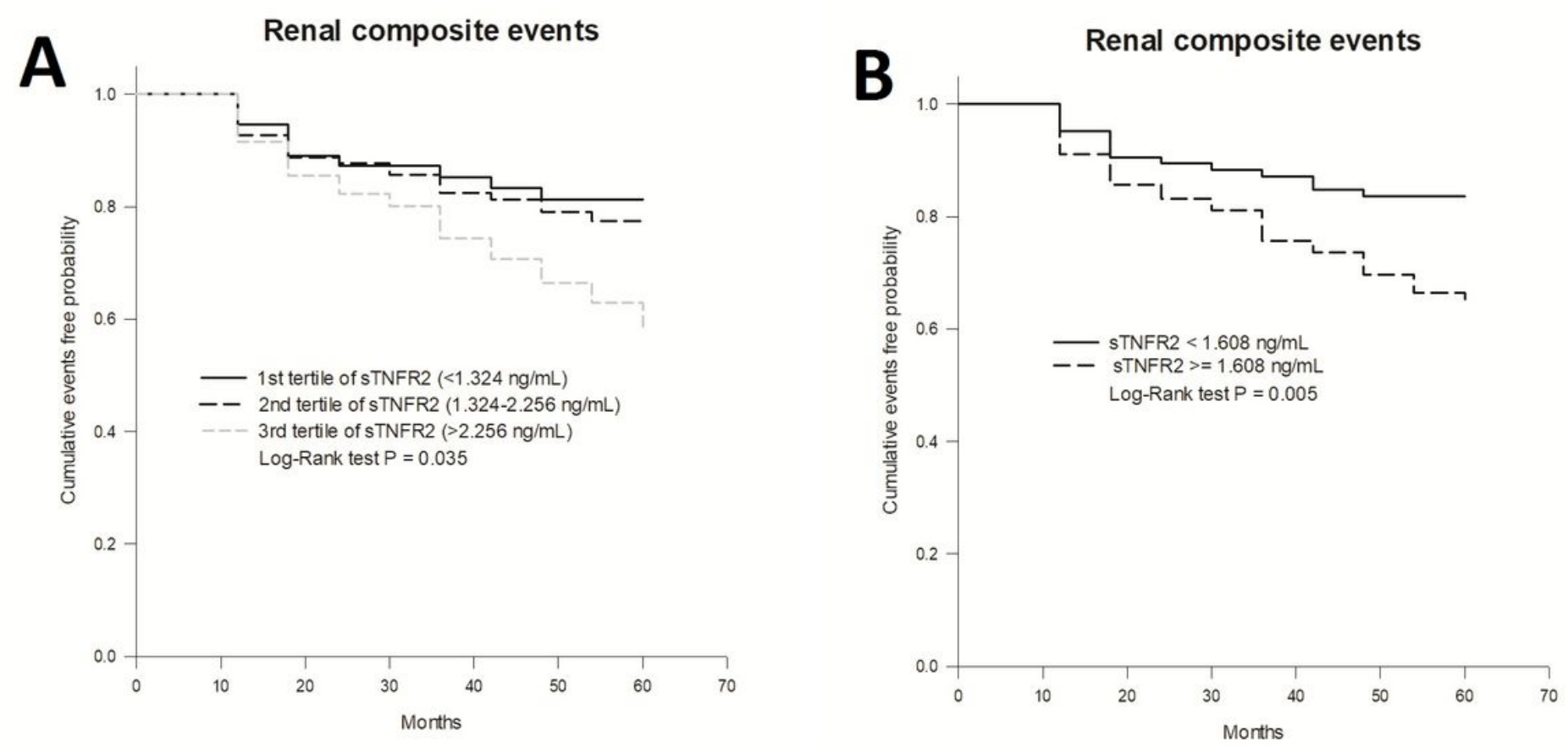

Figure 2 
Kaplan-Meier curves of cumulative event-free survival of renal events (a composite of a $>30 \%$ reduction of the estimated glomerular filtration rate and/or the progression of albuminuria stages) in patients with type 2 diabetes according to: (a) the tertiles of soluble tumor necrosis factor receptor 2 (sTNFR2) levels and (b) the threshold value of sTNFR2 $(\geq 1.608 \mathrm{ng} / \mathrm{mL}$ vs. $<1.608 \mathrm{ng} / \mathrm{mL})$. Differences between curves were analyzed with log-rank statistics. 